\title{
Basic indicators of child health in an urban area in southern Brazil: estimating prevalence rates and evaluating differentials
}

\author{
Juraci A. Cesar, ${ }^{1}$ Raul Mendoza-Sassi, ${ }^{2}$ Bernardo L. Horta, ${ }^{3}$ Paula R. P. Ribeiro, ${ }^{4}$ \\ Alan C. D'Avila, ${ }^{4}$ Fernanda M. Santos, ${ }^{4}$ Priscila B. Martins, ${ }^{4}$ Ralph R. Brandolt ${ }^{4}$
}

\begin{abstract}
Objective: To evaluate and compare basic indicators of the health of children under 5 years old in the urban area of Rio Grande, RS, Brazil, for 1995 and 2004.

Methods: Two cross-sectional population studies were carried out in the city. Interviewers were previously trained and applied standardized questionnaires during visits to families with children under 5 years old. The following variables were investigated: family income, maternal education, type of construction of home (wooden/ masonry etc.), availability of toilet, running water, sewage system and domestic appliances. Data collected on the children themselves included number of antenatal consultations and age at first antenatal, type of delivery and medical care received during delivery, breastfeeding and dietary patterns, morbidity and health services utilization. Children were weighed and measured for height/length. Comparisons of frequencies between the two datasets were made using the chi-square test.

Results: In 1995, 395 children were studied and in 2004 there were 384. During the intervening period improvements had taken place in type of construction, number of homes with flush toilet, the availability of running water and in breastfeeding pattern and duration. The frequency of diarrhea reduced, while rates of basic vaccination coverage, growth monitoring, patients in possession of their own medical cards and reporting of birth weights all increased. There was a deterioration in families' purchasing power and in the mean number of antenatal consultations. The prevalence of childhood obesity increased by $92 \%$, while the incidence of malnutrition remained practically unchanged.
\end{abstract}

Conclusions: Comparing health indicators from the two periods revealed that, in addition to improvements in the majority of the indicators assessed, there had been a substantial increase in the prevalence of childhood obesity.

J Pediatr (Rio J). 2006;82(6):437-44: Child, child health, epidemiology, health indicators, Brazil, crosssectional studies, obesity.

\section{Introduction}

Children under 5 years old remain the principal users of health services in developing countries. They are the first to suffer the impact of any changes in the community.

1. Doutor, Departamento Materno-Infantil, Universidade Federal do Rio Grande (FURG), Rio Grande, RS, e Pós-Graduação em Epidemiologia, Universidade Federal de Pelotas (UFPel), Pelotas, RS.

2. Doutor, Departamento de Medicina Interna, FURG, Rio Grande, RS

3. Doutor, Departamento de Medicina Social e Pós-Graduação em Epidemiologia, UFPel, Pelotas, RS.

4. Acadêmicos de Medicina, FURG, Rio Grande, RS.

Financial support: Secretaria Municipal de Saúde de Rio Grande (RS) and Pastoral da Criança.

Manuscript received Feb 07 2006, accepted for publication Aug 022006

Suggested citation: Cesar JA, Mendoza-Sassi R, Horta BL, Ribeiro PR, D'Avila AC, Santos FM, et al. Basic indicators of child health in an urban area in southern Brazil: estimating prevalence rates and evaluating differentials. J Pediatr (Rio J). 2006;82:437-44.
For this reason, their patterns of sickness and death have been widely employed as indicators of the quality of life of the entire population. ${ }^{1}$ They should therefore be considered, at least on a theoretical plane, a priority group for intervention on the part of government on all levels.

This has meant that, over the last twenty years, countless and successive health surveys have been carried out in several different locations, aiming to determine basic indicators of child health. ${ }^{2-4}$ Knowledge of these indicators, in addition to demonstrating the current status of health and disease, which, in the majority of cases, are unknown to health service providers, also allows for the coverage of programs to be calculated, the impact of interventions already implemented to be evaluated and for future actions to be planned together with the sequence in which they will be carried out. Health surveys are, 
therefore, essential to the providing adequate care at a community level. ${ }^{5}$ It is only with such collective measures, the cost of which must be acceptable to governments, that it will be possible to drastically reduce the close to 10 million child deaths that occur every year globally. 6

The objective of this study was to collect data on basic indicators of the health of children under 5 years old living in the urban area of Rio Grande, RS, and to assess the differences between 1995 and 2004.

\section{Methods}

The city of Rio Grande has around 200 thousand inhabitants and is located a little more than $300 \mathrm{~km}$ from Porto Alegre in the extreme South of Rio Grande do Sul state. Economic activity is based on the port, chemical industries, business and fisheries. It has the sixth largest economy of the state's 497 municipalities. Mean annual income per capita is approximately 4,800 US\$. The public health system consists of two hospitals with 600 Brazilian National Health Service beds (SUS - Sistema Único de Saúde), three large clinics for specialties and 31 health centers where 17 Family Health Program teams are active. In 2004, coefficients of infant and maternal mortality in the city were de $19 / 1,000$ and $67 / 100,000$ live births, respectively. ${ }^{7}$

The data presented in this article originate from two cross-sectional studies of children aged 0 to 59 months living in the urban area of Rio Grande, during the first six months of 1995 and 2004.

Sample size calculation estimates were based on an alpha error of 0.05 , a beta error of 0.20 , exposure and outcome varying from 30 to $60 \%$, relative risk of 1.7 , maximum sampling error of 5.5 percentage points and a maximum of $10 \%$ losses. ${ }^{8}$ Based on these parameters, each study had to enroll at least 387 children under 5 years old.

For both studies it was decided a priori that one third of the geographic divisions defined for censuses would be sampled. Thus, 58 of the 174 sectors were chosen systematically, for each study. Working clockwise, each block and intersection in each sector was numbered and one chosen at random. Starting from the chosen intersection, interviewers visited 28 consecutive homes, seeking children aged 0 to 59 months. When children of that age were found, two standardized questionnaires were applied to the child's mother or guardian. The first questionnaire investigated demographic characteristics of the mother (age, number of household members), socioeconomic status of the family (income, parents' education) and living conditions and sanitation (type of building materials used to construct the family home, number of rooms used for sleeping, type of toilet, household appliances owned, treated water supply, connection to public sewage system). The second questionnaire requested demographic information on the child (age, sex, skin color, number of siblings and date of birth of previous sibling), care received during pregnancy and delivery (gestational age at first prenatal consultation, number of consultations attended, tetanus vaccination, tests performed, type of delivery, who attended the birth, location of birth and birth weight), pattern and duration of breastfeeding and diet (age of weaning off breastfeeding and at introduction of other foods), current nutritional status (weight/age, weight/height and/or height/age deficits), the occurrence of common diseases, such as diarrhea, respiratory infections and skin diseases, and utilization of curative (medical consultations and hospitalizations) and preventative health services (immunizations and growth monitoring). All information was provided by the mother or by the child's guardian; therefore, medical records were not consulted and children were not subjected to any type of clinical examination. Both studies were exactly identical in terms of the method of collecting information and the phrasing of questions.

In order to make possible comparisons with other studies, and to describe the criteria employed here, some variables are defined below:

- Diarrhea: children were classed as having diarrhea if, according to their mothers' reports, they had had three or more soft evacuations during the 24 hours prior to interview;

- Hospitalizations: children were defined as having been hospitalized if they had spent 24 hours or more in a hospital environment during the 12 months prior to interview :

- Nutritional deficit: the National Center for Health Statistics (NCHS) curves were used as a reference, being recommended by the World Health Organization at the time, and deficits were calculated based on age, sex, weight and height (or length in the case of children under 2 years old) ${ }^{9}$. The assessment was based on three indicators: weight for age, weight for height/ length and height/length for age. Children were defined as malnourished if their indicators were below -1.9 standard deviations below the median;

- Overweight/obesity: children were defined as overweight/obesity if their weight/height (or stature) was greater than or equal to 2.0 standard deviations from the mean;

- Basic immunization complete: datum restricted to children aged 12 to 59 months. Children were considered as having completed basic vaccination if they had received three doses of polio and DPT vaccine, and one dose of measles and BCG vaccine. Vaccinations were only considered as confirmed if children's vaccination record cards were produced; 
- Parents' education: measured in completed and passed academic years;

- Family income: the incomes of all household residents during the month immediately prior to interview. Withdrawals from the country's Fundo de Garantia por Tempo de Serviço (FGTS), which is a one-off, length of employment related payment that workers can access under certain circumstances, and unemployment benefit were not included;

- Low birth weight (LBW): children born weighing less than 2,500 grams;

- Confirmation of birth weight: weight recorded on the child's medical card;

- Exclusive breastfeeding: children fed only with breastmilk;

- Predominant breastfeeding: children fed breastmilk plus water or other water-based liquids such as teas and juices;

- Breastfeeding ceased: children are no longer receiving breastmilk;

- Skin color: classified by the interviewer into one of three categories: black, mixed and white;

- Sickness patterns: mothers' definitions were used for skin and respiratory infections. For example, if they said children had "colds" and/or "marks on the skin", these were recorded as respiratory infections and skin infections, respectively.

Twelve academics were recruited, all either undergraduates or post-graduates at the federal universities of Rio Grande and Pelotas and who, preferably, had some experience of this type of work. They were trained for 40 hours to apply the two questionnaires. Training consisted of reading the questionnaires and instruction manuals and simulating interviews.

Next, a pilot study was run in an area that would not be sampled for the main research, with the objective of determining the study's logistic make up, training the interviewers in their approach to families and, most importantly, to test the questionnaires and the process for obtaining the weight and stature of children. After this stage, eight interviewers were selected for data collection, and the remaining four were kept in reserve in the event substitutes were required.

The questionnaires were double input by two different professionals and the results compared. All stages were carried out using Epi-Info $6.02 .^{8}$ Statistical analysis was performed using Stata 7.0.10 Bivariate analysis was used to compare the distribution of variables by year. The magnitudes of any differences were measured using the chi-square test with degree of significance ( $p$ value). ${ }^{11}$

Quality control was performed through review of the questionnaires by a component of the central team and the partial repetition of $5 \%$ of the interviews by the fieldwork supervisors (RPB and EC) and one of the study coordinators (JAC). No significant differences were observed between the information obtained by interviewers, supervisors and the study coordinator. This study was approved by the Research Ethics Committee at the Universidade Federal do Rio Grande.

\section{Results}

Around 1,850 households were visited for each study, finding 411 children under 5 years old in 1995, 395 of whose parents or guardians provided information, representing 3.9\% losses. In 2004, 402 children were identified and information collected on 384 of them, making a total of $4.5 \%$ losses.

Distribution by sex was very similar, in 1995 50.4\% were female and $49.6 \%$ male. In $2004,50.5 \%$ were girls and $49.5 \%$ were boys. With respect of age group, there was no statistically significant difference between 1995 and 2004. Notwithstanding there was a mild predominance of children aged 12 to 23 months, $24.5 \%$ in 1995 against $20.3 \%$ in 2004.

Table 1 contains data on the families' socioeconomic conditions. No improvements were observed in the level of maternal education, with the exception of a small reduction in the percentage of illiterate women in 2004. There was an increase in the proportion of families with incomes of 1 to 2.9 times the minimum monthly wage (MMW) in 2004, but a reduction in the percentage with incomes greater than or equal to $3 \mathrm{MMW}$, in relation to 1995 (Table 2). In terms of mean income, families had a substantial loss over the period, falling from 5.1 MMW in 1995 to 3.2 MMW in 2004.

The data on the types of construction in which people were living revealed an increase in the number of brickbuilt residences and a reduction in wooden structures. There was no significant change to the number of rooms over the period. In 2004, 5.5\% more families had refrigerators than in 1995 . However, there were double the number of homes with wood-burning stoves in 2004. Practically all homes with children under 5 years old received treated water from the public network. Finally, the availability of flush toilets increased from $88 \%$ in 1995 to $94 \%$ in 2004 (Table 1 ).

Table 2 demonstrates that the number of women receiving antenatal care increased, but that the mean number of consultations fell. In 1995, one in every 10 expectant mothers did not attend a single consultation, and the mean number of consultations per expectant mother was 9.4. In 2004, one in every 20 expectant mothers did not attend antenatal consultations, but the mean number had dropped to 8.4. Gestational age at first consultation also remained unchanged over the period. 
Table 1 - Socioeconomic status and living conditions of children under 5 years old in the urban area of Rio Grande, RS, for 1995 and 2004

\begin{tabular}{|c|c|c|c|}
\hline \multirow[t]{2}{*}{ Variable } & \multicolumn{2}{|c|}{ Year } & \multirow[t]{2}{*}{ p value } \\
\hline & 1995 & 2004 & \\
\hline Mothers able to read and write & $93.9 \%$ & $95.3 \%$ & 0.410 \\
\hline \multicolumn{4}{|l|}{ Schooling (completed years) } \\
\hline None & $4.8 \%$ & $4.7 \%$ & 0.541 \\
\hline $1-4$ & $23.5 \%$ & $20.8 \%$ & \\
\hline $5-8$ & $46.6 \%$ & $45.0 \%$ & \\
\hline$>9$ & $25.1 \%$ & $29.5 \%$ & \\
\hline Mean (standard deviation) & $6.8(4.0)$ & $6.9(3.4)$ & 0.71 \\
\hline Family income (multiples of monthly minimum wage) & $(366)$ & $(370)$ & \\
\hline$<1$ & $12.1 \%$ & $12.7 \%$ & 0.003 \\
\hline $1-1.9$ & $19.5 \%$ & $33.5 \%$ & \\
\hline $2-2.9$ & $18.0 \%$ & $20.3 \%$ & \\
\hline $3-5.9$ & $23.5 \%$ & $20.8 \%$ & \\
\hline$>6$ & $20.2 \%$ & $12.7 \%$ & \\
\hline Mean (standard deviation) & $5.1(4.4)$ & $3.2(3.7)$ & 0.000 \\
\hline \multicolumn{4}{|l|}{ Type of structure } \\
\hline Masonry & $75.9 \%$ & $78.7 \%$ & 0.056 \\
\hline Wooden & $14.4 \%$ & $9.2 \%$ & \\
\hline Others & $9.6 \%$ & $12.1 \%$ & \\
\hline \multicolumn{4}{|l|}{ Number of rooms used for sleeping } \\
\hline One & $32.4 \%$ & $34.2 \%$ & 0.399 \\
\hline Two & $53.9 \%$ & $49.5 \%$ & \\
\hline Three or more & $13.7 \%$ & $16.3 \%$ & \\
\hline \multicolumn{4}{|l|}{ Appliances } \\
\hline Radio & $94.4 \%$ & $91.8 \%$ & 0.153 \\
\hline TV & $94.9 \%$ & $93.2 \%$ & 0.294 \\
\hline Refrigerator & $86.6 \%$ & $91.6 \%$ & 0.026 \\
\hline Gas cooker & $99.7 \%$ & $97.6 \%$ & 0.320 \\
\hline Wood-fired stove & $5.4 \%$ & $11.3 \%$ & 0.005 \\
\hline \multicolumn{4}{|l|}{ Running water inside home } \\
\hline Yes & $93.3 \%$ & $96.6 \%$ & 0.036 \\
\hline No & $6.7 \%$ & $3.4 \%$ & \\
\hline \multicolumn{4}{|l|}{ Origin of water } \\
\hline Public system & $99.5 \%$ & $99.8 \%$ & 0.973 \\
\hline Others & $0.5 \%$ & $0.2 \%$ & \\
\hline \multicolumn{4}{|l|}{ Type of toilet } \\
\hline Flush toilet & $88.1 \%$ & $94.0 \%$ & 0.001 \\
\hline Other & $9.1 \%$ & $1.5 \%$ & \\
\hline None & $2.8 \%$ & $4.5 \%$ & \\
\hline Total & $100 \%(395)$ & $100 \%(384)$ & \\
\hline
\end{tabular}

Only $2 / 3$ of women began prenatal during the first trimester of pregnancy. The percentage de women who had received at least one dose of tetanus vaccine remained low, with coverage of little more than $1 / 3$.

Almost all children were born in hospital, and the great majority of deliveries were performed by physicians. In $1995,77 \%$ of children were delivered by doctors, compared with $87 \%$ in $2004(p=0.001)$. The percentage of caesarians remained elevated in 2004 (40.1\%).
Confirmation of birth weight also increased by around $25 \%$ over the period, increasing from $63 \%$ in 1995 to $79 \%$ in 2004. Finally, both the prevalence of LBW $(<2,500 \mathrm{~g})$ and mean weight of the children was very similar for the two periods, 3,166 grams in 1995 and 3,168 grams in 2004 (Table 2).

Table 3 demonstrates that there had been significant improvements in relation to breastfeeding. The children studied in 2004 were fed at their mothers breasts for 
Table 2 - Healthcare during gestation and delivery of children under 5 years old in the urban area of Rio Grande, RS, for 1995 and 2004

\begin{tabular}{|c|c|c|c|}
\hline \multirow[t]{2}{*}{ Variable } & \multicolumn{2}{|c|}{ Year } & \multirow[t]{2}{*}{ p value } \\
\hline & 1995 & 2004 & \\
\hline \multicolumn{4}{|l|}{ Number of antenatal consultations attended } \\
\hline 1 or more & $90.9 \%$ & $94.0 \%$ & 0.100 \\
\hline 6 or more & $77.7 \%$ & $74.0 \%$ & 0.220 \\
\hline 14 or more & $12.7 \%$ & $8.3 \%$ & 0.049 \\
\hline Mean (standard deviation) & $9.4(4.1)$ & $8.4(4.4)$ & 0.017 \\
\hline Trimester during which first prenatal was attended & $(355)$ & $(361)$ & \\
\hline First & $63.4 \%$ & $65.7 \%$ & 0.481 \\
\hline Second & $31.5 \%$ & $31.0 \%$ & \\
\hline Third & $5.1 \%$ & $3.3 \%$ & \\
\hline Received at least one dose of tetanus vaccine during prenatal & $30.1 \%$ & $31.3 \%$ & 0.720 \\
\hline \multicolumn{4}{|l|}{ Location of birth } \\
\hline Hospital & $98.7 \%$ & $99.0 \%$ & 0.767 \\
\hline Other & $1.3 \%$ & $1.0 \%$ & \\
\hline \multicolumn{4}{|l|}{ Care during delivery } \\
\hline Physician & $77.5 \%$ & $87.0 \%$ & 0.001 \\
\hline Others & $22.5 \%$ & $13.0 \%$ & \\
\hline \multicolumn{4}{|l|}{ Type of delivery } \\
\hline Normal & $55.7 \%$ & $59.9 \%$ & 0.235 \\
\hline Caesarian & $44.3 \%$ & $40.1 \%$ & \\
\hline \multicolumn{4}{|l|}{ Information on birth weight } \\
\hline Confirmed & $63.2 \%$ & $79.4 \%$ & 0.000 \\
\hline Reported & $36.8 \%$ & $20.6 \%$ & \\
\hline \multicolumn{4}{|l|}{ Birth weight (g) } \\
\hline$<2,500$ & $11.8 \%$ & $10.2 \%$ & 0.474 \\
\hline $2,500-2,999$ & $23.5 \%$ & $25.3 \%$ & \\
\hline $3,000-3,499$ & $35.3 \%$ & $39.0 \%$ & \\
\hline$>3,500$ & $29.4 \%$ & $25.5 \%$ & \\
\hline Mean (standard deviation) & $3.167(610)$ & $3.168(539)$ & 0.98 \\
\hline Total & $100 \%(395)$ & $100 \%(384)$ & \\
\hline
\end{tabular}

longer than those studied in 1995. Median exclusive breastfeeding in 2004 was around 1 month longer than in 1995.

There were substantially more children in 2004 with basic vaccination complete (polio, triple viral, measles and BCG) than in 1995. With the exception of BCG, the increases were approximately $30 \%$ for all vaccines over the period. Possession of medical cards, for all children, and weighing, for those less than 2 years old, were much more widespread among the 2004 sample. The total numbers of children who had medical cards and who had been weighed during the previous month were, respectively, 2.3 and 4.5 times greater in 2004 than in 1995 (Table 4).

Deficits in weight/stature, weight/age and stature/age remained practically stable in the two studies. Nevertheless, the prevalence of overweight/obesity increased by around $90 \%$, from approximately 8 to $15 \%$ (Table 4 ). There was a significant reduction in the number of consultations attended by under fives during the 3 months prior to interview, particularly for diarrhea, but an increase in the number of consultations due to skin infections. Both hospitalization rates and primary causes for admission were practically stable between the two studies. There was a drastic reduction in the occurrence of diarrhea: the incidence of diarrhea on the day of interview dropped from 6.3 to $1.3 \%$, while prevalence during the previous 2 weeks dropped from 13 to $5 \%$ (Table 4 ).

\section{Discussion}

This study has shown that, between 1995 and 2004, there was a small improvement in living conditions, in the pattern and duration of breastfeeding and the occurrence of diarrhea among children under 5 years, living in the urban area of Rio Grande, RS. There was also a significant 
Table 3 - Breastfeeding patterns among children under 5 years old in the urban area of Rio Grande, RS, for 1995 and 2004

\begin{tabular}{|c|c|c|c|}
\hline \multirow[t]{2}{*}{ Variable } & \multicolumn{2}{|c|}{ Year } & \multirow[t]{2}{*}{ p value } \\
\hline & 1995 & 2004 & \\
\hline \multicolumn{4}{|c|}{ Percentage of children breastfeeding at } \\
\hline 1 day & $88.7 \%$ & $87.8 \%$ & \\
\hline 1 month & $75.7 \%$ & $81.7 \%$ & \\
\hline 3 months & $58.1 \%$ & $63.9 \%$ & \\
\hline 6 months & $36.3 \%$ & $43.7 \%$ & \\
\hline 12 months & $15.1 \%$ & $28.3 \%$ & \\
\hline Median (in months) & 3.65 & 4.49 & 0.021 \\
\hline \multicolumn{4}{|c|}{ Children exclusively breastfeeding at } \\
\hline 1 month & $34.6 \%$ & $59.2 \%$ & \\
\hline 3 months & $10.6 \%$ & $26.5 \%$ & \\
\hline 6 months & $1.4 \%$ & $4.3 \%$ & \\
\hline 12 months & $0.0 \%$ & $0.0 \%$ & \\
\hline Median (in months) & 0.76 & 1.53 & 0.053 \\
\hline \multicolumn{4}{|c|}{ Children predominantly breastfeeding at } \\
\hline 1 month & $65.9 \%$ & $74.0 \%$ & \\
\hline 3 months & $39.9 \%$ & $46.7 \%$ & \\
\hline 6 months & $2.8 \%$ & $9.2 \%$ & \\
\hline 12 months & $0.4 \%$ & $0.0 \%$ & \\
\hline Median (in months) & 2.33 & 2.82 & 0.032 \\
\hline Total & $100 \%(395)$ & $100 \%(384)$ & \\
\hline
\end{tabular}

increase in the prevalence of overweight/childhood obesity. Furthermore, utilization of certain preventative health services (immunizations and growth monitoring) and the children's record-keeping system (possession of a medical card and confirmation of birth weight) improved substantially.

When interpreting this data, it is necessary to bear in mind that these are cross-sectional studies, whose results presented are strictly representative of the period when they were collected. ${ }^{12}$ Furthermore, the samples were restricted to the urban area, not, therefore reflecting the health conditions of children under 5 years old resident throughout the municipality. The recommendations set out below are only applicable to the city of Rio Grande.

The improvements in living conditions are probably the result of the poorest families having increased their purchasing power, of lower numbers of people per household, due to a drop in the population's growth rate, 3,13 and of investment by local government, in particular the construction of low-cost housing.

While there was an increase in median breastfeeding duration over the period, the 4.5 months observed were well below levels that have been achieved for Brazil (9.9 months) and the South Region (7.5 months). ${ }^{14}$ It is, therefore, necessary to promote and support breastfeeding from prenatal care up to the first months after birth, particularly the first weeks, the period of greatest breastfeeding cessation, and also to reinforce those programs already running in the municipality, such as, for example, the Baby Friendly Hospital Initiative.

The improved sanitary conditions and increased duration of breastfeeding, particularly exclusively, may be contributing to the reduction in diarrhea occurrence among the children of Rio Grande. Despite significant differences between regions, reductions in mortality due to diarrhea has been observed for Brazil as a whole. ${ }^{15}$

The improvement observed in vaccination coverage is also very similar to the rest of Brazil, which is taking great strides towards universal immunization of under-5s and the eradication of diseases ${ }^{16}$ that can be prevented by vaccination.

The increase of confirmation of birth weights by recording them on children's medical cards reveals that health services and parents are valuing information on children more.

In common with other parts of Brazil, growth monitoring has increased substantially. Weighing children is one of the more frequently carried-out activities, for example, by community health workers during home visits. Nevertheless, this is an activity that has little impact of 
Table 4 - Health services utilization and morbidity patterns among children under 5 years old in the urban zone of Rio Grande, RS, for 1995 and 2004

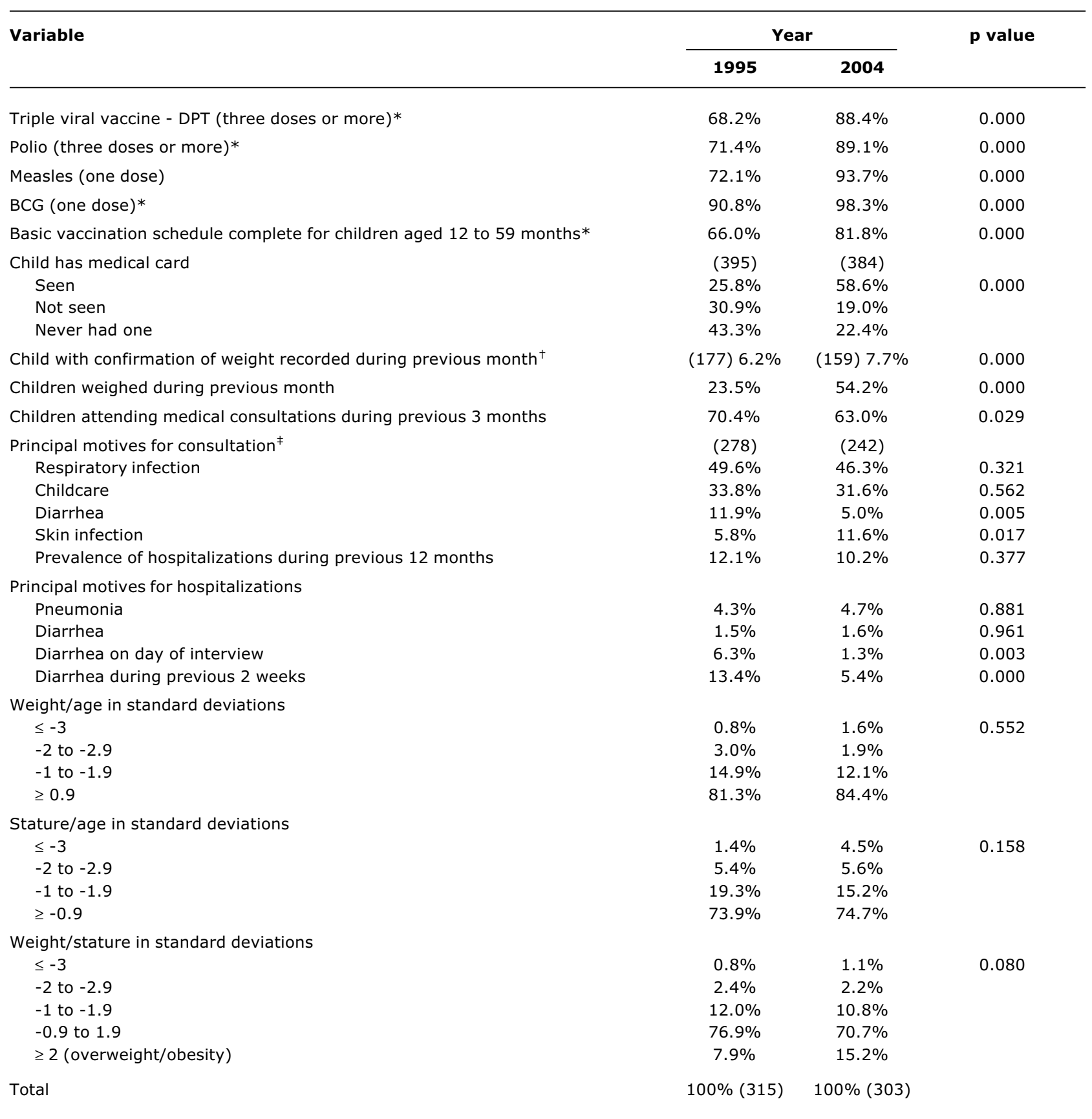

* Children aged 12 to 59 months.

$\dagger$ For children aged 0 to 23 months.

$\ddagger$ The total number may exceed $100 \%$ because one child may have attended more than one consultation for different reasons.

children's health, since, in the case of Rio Grande, which has no program for the recovery of malnourished children or for the management of overweight or obese children, weighing children does not imply more effective interventions. For this reason, there is a need to rethink this procedure at the local level, which is already happening in other locations. ${ }^{17}$

Finally, obese children have substantially higher risks of becoming ill and dying early during adulthood from chronic diseases. ${ }^{18}$ In Rio Grande, child obesity is increasing 
and is a health problem more common than any nutritional deficit. Not just because of its prevalence, but also because of the potential damage it can cause, this is a problem that must be faced as a challenge in child health over the coming decades in all social classes in the location studied.

Concluding, the basic indicators of the health of children in Rio Grande are better than 10 years ago, but remain well below ideal. Infant mortality, for example, dropped from $24 / 1,000$ in 1995 to $19 / 1,000$ in 2004, ${ }^{7}$ which is very little considering the economic power of the city and its healthcare infrastructure. In order to improve these indicators, certain measures can be adopted, such as: 1 ) give the care of children priority in public health services; 2) face childhood overweight/obesity as a severe and emerging health problem requiring immediate action, both in terms of preparing health professionals for the adequate management of this disease; 3 ) maintain the achievements already won, such as, for example, improved vaccination coverage; 4) increase the duration of breastfeeding, particularly exclusively; 5) take account of the peculiarities of the municipality, such as, for example, the elevated occurrence of respiratory diseases, ${ }^{19}$ when national programs are implemented; 6 ) define interventions based on their potential for impact and at the lowest cost possible; and 7) periodically assess health programs offered to the mother and baby population.

\section{Acknowledgements}

Thanks are due to the Municipal Health Department of Rio Grande, to Pastoral da Criança for supporting these surveys, and also to the many professionals who took part in the various stages of the study: Denise Medeiros, Patrícia Souza Mano, Rodrigo Campos Pereira, Alessandra Diziekaniak, Eduardo F. Ulmi, Joel Antonio O. Filho, Rossana P. Basso and Elisabete Cardoso.

\section{References}

1. Kerr-Pontes LR, Rouquayrol MZ. Medida da saúde coletiva. In: Rouquayrol MZ, Almeida-Filho NM. Epidemiologia e saúde. $6 a$ ed. Rio de Janeiro: MEDSI; 2003. p. 37-82.

2. MacAuliffe J, Correia L, Granjeiro GP. Terceira pesquisa de saúde materno-infantil do Ceará, 1994. Fortaleza: Secretaria de Saúde do Ceará/UNICEF; 1995.

3. Monteiro CA, Nazario CL. Evolução de condicionantes ambientais da saúde na infância na cidade de São Paulo (1984-1996). Rev Saude Publica. 2000;34:13-8.
4. Cesar JA, Cavaletti MA, Holthausen R, Lima LG. Mudanças em indicadores de saúde infantil em um município com agentes comunitários: o caso de Itapirapuã Paulista, Vale do Ribeira, São Paulo, Brasil. Cad Saude Publica. 2002;18:1647-54.

5. Vaughan JP, Morrow R. Epidemiologia para municípios: manual para gerenciamento dos distritos sanitários. São Paulo: Hucitec; 1992.

6. Black RE, Morris SS, Bryce J. Where and why are 10 million children dying every year? Lancet. 2003;361:2226-34.

7. Núcleo de Informações em Saúde. Coeficiente de mortalidade infantil e ocorrência de óbitos maternos por município. Porto Alegre: Secretaria de Estado da Saúde do Rio Grande do Sul; 2005.

8. Dean AG, Dean JA, Coulombier D, Brendel KA, Smith DC, Burton $\mathrm{AH}$, et al. Epi-Info, Version 6: A Word Processing, Database, and Statistics Program for Epidemiology on Microcomputers. Atlanta: Centers of Disease Control and Prevention; 2002.

9. National Center for Health Statistics. Growth curves for children, birth -18 years. United States. Department of Health, Education and Welfare (PHS). Hyattsville: NCHS; 1977. (Publ No 78-1650, Série 11 No 165.)

10. StataCorp. Stata statistical software: release 7.0. College Station: Stata Corporation; 2001.

11. Kirkwood BR. Essential of Medical Statistics (1988). London: Blackwell Scientific Publications; 2001.

12. Kelsey JL, Whittemore AS, Evans AS, Thompson WD. Methods in Observational Epidemiology. New York: Oxford University Press; 1996. p. 244-67.

13. Tomasi E, Barros FC, Victora CG. Situação sócio-econômica e condições de vida: comparação de duas coortes de base populacional no Sul do Brasil. Cad Saude Publica. 1996;12:15-9.

14. Ministério da Saúde. Prevalência de aleitamento materno nas capitais brasileiras e no Distrito Federal. Brasília [Relatório de pesquisa]; 2001.

15. Victora CG, Cesar JA. Saúde materno-infantil no Brasil: padrões de morbidade e possíveis intervenções. In: MZ Rouquayrol e Almeida-Filho NM. Epidemiologia e saúde. 6a ed. Rio de Janeiro: MEDSI; 2003. p. 415-67.

16. Ministério da Saúde. DATASUS. http://w3.datasus.gov.br/ datasus/datasus.php ?area =359A1B375C2D0E0F359G19 HIJd2L2412MON\&VInclude $=. . /$ site/infsaude.php. Access: 31/ $04 / 2006$.

17. Save the children. Thin on the ground: questioning the evidence behind World Bank-funded community nutrition projects in Bangladesh, Ethiopia and Uganda. London: The Save the Children; 2003.

18. World Health Organization. Obesity: preventing and managing the global epidemic. Geneva: WHO; 1997.

19. Prietsch SO, Fischer GB, Cesar JA, Fabris AR, Mehanna H, Ferreira $\mathrm{TH}$, et al. Doença aguda das vias aéreas inferiores em menores de cinco anos: influência do ambiente doméstico e do tabagismo materno. J Pediatr (Rio J). 2002;78:415-22.

\section{Correspondence:}

Juraci A Cesar

Pós-Graduação em Epidemiologia, Universidade Federal de Pelotas Avenida Duque de Caxias, 250, 30 andar, Bairro Fragata

Caixa Postal, 464

CEP 96030-002 - Pelotas, RS - Brazil

Tel./Fax: +55 (53) 3271.2442

E-mail: jacesar@terra.com.br 